\title{
Prevalence of types of dental abscesses in preschool and kindergarten patients referring to Apple Dental Clinic in Shiraz in 2015
}

\author{
Mohammad Karimi* \\ Apple Dental Clinic, Iran
}

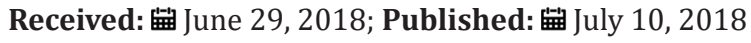

*Corresponding author: Mohammad Karimi, Apple Dental Clinic, Shahid Rezaeist., in front of Hejab pool, Shiraz, Iran

\begin{abstract}
Introduction: The purpose of this study was the evaluation of the prevalence of dental abscesses, treatment and healing rate in preschool and kindergarten children who were referred to Apple Dental Clinic.

Materials \&Methods: This descriptive study is based on the clinical evaluations of children up to age 6 with dental infections. During this study, 100 children ( 60 girls, 40 boys) were evaluated.

Results: In this evaluation, 100children were studied and evaluated. The most prevalence was in 5 to 6 years old children (48\%), among which $25 \%$ were acute abscess. The most involved teeth were $\mathrm{D}$ and $\mathrm{E}$ in the lower arch.The major treatments were including the combination of drainage, pulpectomy and antibiotic therapy.

Conclusion: As the research and statics analysis has showed, the high prevalence of dental abscess in primary molars, it is advisable to maintain these teeth before the permanent molars eruption. It is necessary to do early diagnosis and treatment of dental caries and abscesses before it is too late
\end{abstract}

Keywords: Preschool and Kindergarten Patients; Primary Molars; Dental Abscesses

\section{Introduction}

Unfortunately, in our society, the high prevalence of caries and the incidence of dental abscesses in children, especially in kindergartens and preschool children are quite evident. This can be due to an inappropriate diet of children, including excessive consumption of sweets and junk foods, poor oral and dental hygiene of children, parents 'negligence in this matter, and parents' lack of awareness of the importance of preserving children teeth[1]. From another perspective on this issue, it seems that numerous dental abscesses in children can lead to the loss of primary teeth, dysfunction of the chewing and dental occlusion of the patient, loss of dental spaces and, eventually, anomalies of Jaw and teeth. Due to contact with the oral and dental environment of children with different microorganisms, the head and neck can be at risk for infection in those areas, especially the dental infection caused by bacterial infection[2]. The infiltration of infections in the bone tissue of children's jaws often does not cause severe pain but spreading this inflammation can seriously damage the dental buds. The aim of this research was to evaluate the prevalence of dental abscesses, treatment status and the rate of recovery in children aged 3-6 years who referred to the Apple Dental Clinic.

\section{Materials \&Methods}

This study is based on observations, completed questionnaires for each child, examination of children for dental infections and the results recorded in the questionnaires. During the study, 100 children with dental abscess (60 girls and 40 boys) who were from kindergarten and preschool were examined[3]. Initially, basic information was obtained regarding the history of pain, the chief complaint of the patient, the course of the disease, and the signs and symptoms of the infection. Most of the referred childrenwere also examined for infection, swelling and pus accumulation. In cases of acute abscess, the primary emergency measures included abscess drainage and antibiotic treatment.Patients were re-evaluated after 24-hours, and information was obtained on the history of pain, gingival condition and tissues inflation around the teeth. Finally, the final information was collected, categorized and then the conclusions were analyzed [4]. 


\section{Findings}

Out of 100 referral patients, 60 (60\%) girls and 40 (40\%) were boys. The minimum age of patients was 3 years old and maximum 6 years old. The age group of 5 to 6 years old was the most frequent. The frequency of acute abscess in children younger than 5 years was $52.6 \%$ and in chronic abscess $47.7 \%$. In children aged 5-6 years, the percentage of acute abscess was $57.7 \%$ and in the chronic abscess $47.7 \%$ (Table 1).The prevalence of dental abscesses in teeth $\mathrm{D}$ and E of the lower jaw is more than maxilla (Table 2).Most patients, who referred with pain, had acute abscesses. The prevalence of abscess in mandible was greater than maxillary (Table 1).Treatments for patients included antibiotic therapy, abscess drainage, pulpectomy and extraction of necrosis tooth[5].

Table 1: The abundance of patients under study based on gender, type of abscess, age, pain,site of occurrence.

\begin{tabular}{|c|c|c|c|}
\hline Gender & Acute & Chronic & Summation \\
\hline Girl & $20(33.3 \%)$ & $40(66.7 \%)$ & 60 \\
\hline Boy & $18(45 \%)$ & $22(55 \%)$ & 40 \\
\hline $\begin{array}{c}\text { Less than } 5 \\
\text { years old }\end{array}$ & $9(52.9 \%)$ & $8(47.1 \%)$ & 17 \\
\hline 5 to 6years old & $27(56.2 \%)$ & $21(43.8 \%)$ & 48 \\
\hline Pain & $41(80.4 \%)$ & $10(19.6 \%)$ & 51 \\
\hline Upper jaw & $20(52.6 \%)$ & $18(47.4 \%)$ & 38 \\
\hline Lower jaw & $30(57.7 \%)$ & $27(47.4 \%)$ & 57 \\
\hline
\end{tabular}

Table 2: Number of dental abscesses in teeth of D, E in both jaws.

\begin{tabular}{|c|c|c|c|}
\hline Tooth number & Girl & Boy & Total sum \\
\hline D upper jaw & 15 & 5 & 20 \\
\hline D lower jaw & 19 & 12 & 31 \\
\hline E upper jaw & 14 & 3 & 35 \\
\hline E lower jaw & 25 & 17 & 42 \\
\hline
\end{tabular}

\section{Discussion}

Of the 100 examined dental abscesses, 65 were re-examined, but 35 cases unfortunately did not return back for follow up. At the first session, the importance of oral and dental health and the complications of dental abscesses for parents were fully explained. Possible reasons for not referring to a re-examination can be summarized below: The lack of cooperation of the child, the lack of awareness of parents regarding the importance of maintaining the teeth and the complications of tooth loss, pain relief, and reluctance to continue to treat or tooth extraction due to high dental treatment costs[6]. According to this study, it could be argued why the prevalence of dental abscesses in girls $60 \%$ is higher than that of boys? Perhaps the answer can be summarized in the following: excessive consumption of junk foods and sweets and consuming very soft foods is involved.

\section{Conclusion}

Knowing what causes tooth abscess in kids makes it easier to prevent it. A bacterial infection in the mouth is the primary reason for an abscess, a condition in which the tooth has one or more pockets of pus connected to it. Tooth decay is the primary cause of a dental abscess in children.In the development of dental abscesses in children, there are a number of factors that affect. The most important factor is poor oral and dental health in children, which causes tooth decay and as a result of damage totooth pulp will lead to dental abscess. Among other factors, parents' weakness and disability in keeping good oral hygiene of their children and the lack of knowledge of parents' dentistry about the importance of primary teeth, should be emphasized.The launch of an oral health plan for kindergartens and preschoolers, the dissemination of information about preventive pediatric dentistry for parents and organizing monthly oral and dental care sessions with parents can have a significant effect on the teeth maintenance of these children. Finally, a comprehensive pediatric dentistry plan can have a serious impact on reducing the prevalence of dental abscesses in children.

\section{References}

1. Coticchia JM, Getnick GS, Yun RD, Arnold JE (2004) Age, site and timespecific differences in pediatric deep neck abscesses. Arch Otolaryngol Head Neck Surg 130(2): 201-207.

2. Braham RL, Morris ME (1990) Text book of pediatric dentistry ( $\left.2^{\text {nd }} E d n\right)$. Baltimore: Williams \& Wilkins 327: 421-422.

3. Dodson TB, Perrott DH, Kaban LB (1989) Pediatricmaxillofacial infections: a retrospective study of 113 patients. J Oral Maxillofac Surg 47(4): 327-330.

4. AW Chow, SM Roser, FA Brady (1978) Orofacial odontogenic infections. Ann Intern Med 88(3): 392-402.

5. Stewart RE, Thomas KB, Troutman KE, Hywei S (1982) Pediatric dentistry scientific foundations and clinical practice. ( $\left.2^{\text {nd }} E d n.\right) . p p .976-$ 979.

6. Regezi JA, Sciubba JI, Pogrel MA (2000) Atlas of oral and maxillofacial

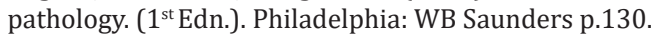

\section{ISSN: 2574-1241}

DOI: $10.26717 /$ BJSTR.2018.06.001373

Mohammad Karimi. Biomed J Sci \& Tech Res

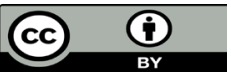

This work is licensed under Creative Commons Attribution 4.0 License

Submission Link: https://biomedres.us/submit-manuscript.php

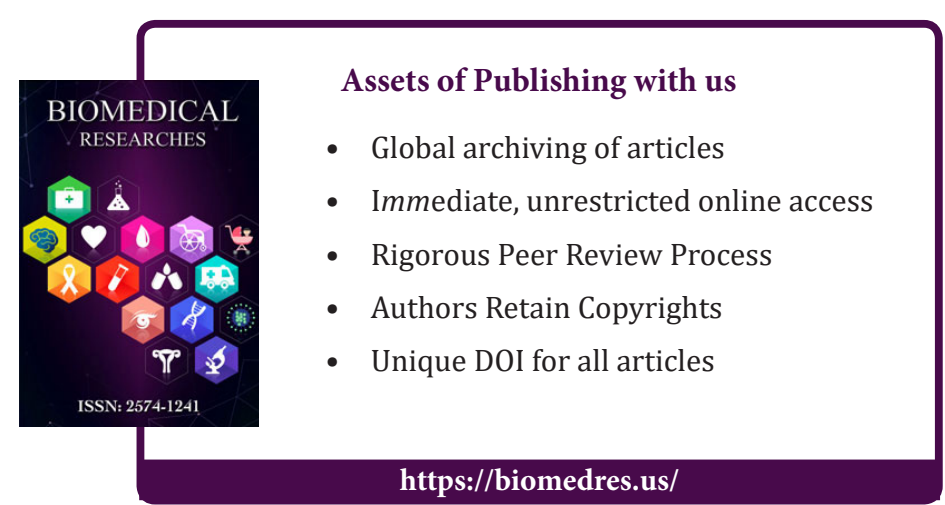

Cite this article: Mohammad K. Prevalence of types of dental abscesses in preschool and kindergarten patients referring to Apple Dental Clinic in Shiraz in 2015. Biomed J Sci\&Tech Res 6(4)- 2018. BJSTR. MS.ID.001373. DOI: 10.26717/ BJSTR.2018.06.001373. 